\title{
The Burden of X-Linked Retinitis Pigmentosa on Patients and Society: A Narrative Literature Review
}

\author{
Marie Chivers' \\ $\mathrm{Nan} \mathrm{Li} \mathbb{1}^{2}$ \\ Feng $\operatorname{Pan}^{2}$ \\ Heather Wieffer' \\ Rafal Slowik (D) ${ }^{2}$ \\ Jittrakul Leartsakulpanitch ${ }^{2}$
}

'PRMA Consulting, Fleet, Hampshire, UK; ${ }^{2}$ Janssen Global Services,LLC, Raritan, NJ, 08869, USA
Correspondence: $\mathrm{Nan} \mathrm{Li}$

Janssen R\&D, Raritan, NJ, 08869, USA

Tel +l 267-810-4007

Email nli47@its.jnj.com
Abstract: X-linked retinitis pigmentosa (XLRP) is a severe form of retinitis pigmentosa (RP), a rare, inherited retinal degenerative disorder, that causes blindness. The aim of this literature review was to identify what is currently known about the burden of XLRP. Literature databases were searched for articles describing the clinical, humanistic, or economic burden of XLRP or RP in the US, Japan, France, Germany, Italy, Spain, and the UK, published in English between 2014 and 2019; gray literature and cited references were reviewed. Literature describing XLRP is limited as this is an ultra-rare condition; findings relating to burden of RP have been reported with interpretation of how burden differs for XLRP. In XLRP, night blindness usually presents in the first decade of life, followed by loss of peripheral and then central vision; legal blindness is reported at a median of 45 years in affected males (vs median 70 years for RP). There is limited evidence of humanistic or economic burden specific to XLRP; one study identified greater vision-related activity limitations in patients with XLRP compared with the wider RP population. Qualitative studies describe increased humanistic burden for people living with RP; difficulty undertaking everyday tasks (driving, hobbies, reading), psychosocial burden and barriers to work and career. People described the emotional impact of dealing with progression of RP, ongoing social and physical challenges, and the impact of RP on relationships. The economic burden of RP is associated with lost productivity, greater healthcare costs and increasing requirement for formal and informal care. In summary, XLRP remains an untreatable condition that can impact people from childhood. The humanistic burden of RP has been shown to increase as the disease progresses; hence, in XLRP the earlier onset and earlier progression to blindness during prime working years may mean a comparatively greater lifetime burden of disease.

Keywords: X-linked retinitis pigmentosa, burden, quality of life, health economics

\section{Introduction}

$\mathrm{X}$-linked retinitis pigmentosa (XLRP) is a severe form of retinitis pigmentosa (RP) that primarily affects males. RP is a rare genetic condition associated with progressive breakdown and loss of photoreceptors (ie, rod cells for peripheral and night vision, and cone cells for central and color vision) leading to blindness in both eyes. ${ }^{1}$ There are differences in the age of onset, rate of progression, and secondary clinical manifestations between different forms of RP; XLRP is one of the most aggressive forms of this disease. ${ }^{2,3}$ XLRP is associated with mutations in genes located on the $\mathrm{X}$ chromosome, which means the condition predominantly affects males. However, some female carriers may also be clinically affected, although usually with a much less severe phenotype than males: the variability in phenotypes 
among female carriers is attributed to the pattern of random inactivation of the $\mathrm{X}$ chromosome carrying the wildtype gene during development of retinal tissue, moderated by other genetic and environmental factors. ${ }^{4,5}$

XLRP is most commonly caused by mutations in the Retinitis Pigmentosa GTPase Regulator $(R P G R)$ gene on the $\mathrm{X}$ chromosome. ${ }^{6} \mathrm{XLRP}$ associated with $R P G R$ mutations presents with early onset of night blindness, often within the first 10 years of life; ${ }^{4}$ vision loss progresses to legal blindness by a median age of 45 years. ${ }^{3}$ Female carriers of XLRP associated with $R P G R$ mutations have a range of clinical presentations and a slower disease trajectory. $^{7,8}$

Currently, no treatment is available for XLRP; recommended management is as for RP (in the absence of XLRP-specific guidelines) and includes low-vision rehabilitation and use of optical aids. ${ }^{2}$ Therapies in development include gene therapy and stem cell therapeutics; these treatment strategies may improve the management of inherited retinal diseases in the coming years. ${ }^{9,10}$

A comprehensive literature review was conducted to establish what is known about the burden of XLRP, to better understand the potential impact of therapies currently in development, and to increase awareness of the clinical, humanistic, and economic burden associated with this rare disease. Given the anticipated lack of data specific to XLRP, evidence from the broader population of patients with RP was reviewed and the interpretation of this for the XLRP population then considered.

\section{Methodology}

This literature review focused on the clinical, humanistic, and economic burden of XLRP in a range of developed countries (the US, Japan, France, Germany, Italy, Spain, and the UK). Literature databases (MEDLINE, Embase, and Cochrane Reviews) were searched, limited to publications from January 2014 to October 2020. The search strategy was constructed using combinations of various key terms for X-linked retinitis pigmentosa, retinitis pigmentosa, burden, countries within scope, and healthrelated quality of life (HRQL) (Supplementary Table 1). The aggregate terms "inherited retinal disease" and "retinal dystrophy" were also employed to avoid exclusion of studies that presented data on a broader group of conditions. Screening criteria were applied to the search results (see Supplementary Table 1 for eligibility criteria, Supplementary Table 2 for inclusion criteria). The literature search was supplemented by searches of gray literature to include websites of clinical and patient organizations, conference abstracts, health technology assessments, and targeted searches of Google and Google Scholar using keywords (see Supplementary Table 3 for search databases and sources). Due to the scarcity of literature on this topic, publications were reviewed to identify relevant cited references with earlier publication dates.

\section{Results}

\section{XLRP is a Rare Disease, Most Cases of Which are Attributable to Mutations in the RPGR Gene}

$\mathrm{RP}$ is a rare condition with an estimated incidence of 1 case for every 3700 individuals in the US. ${ }^{11}$ The proportion of RP that is XLRP varies regionally, with estimates ranging from $2 \%$ in Japan ${ }^{12}$ to between $6 \%$ and $16 \%$ in the US. ${ }^{11,13}$ XLRP was caused by mutations in the RPGR gene in more than $70 \%$ of XLRP-affected families in studies conducted in France and Germany. ${ }^{14,15}$ XLRP is less frequently caused by mutations in the RP2 and OFD1 genes. ${ }^{16}$ Findings from the literature review relating to the prevalence of RP and XLRP in different countries are summarized in Table 1.

\section{Symptoms of XLRP Present in Childhood and Progress to Legal Blindness by a Median Age of 45 Years in Affected Males}

In males with XLRP, night blindness is often the first symptom to present, with a median age of onset of 6 years reported in a clinical study of 13 affected males; ${ }^{4}$ peripheral vision remains relatively well preserved up to the first decade and then begins to worsen. ${ }^{4,22}$ Vision loss meeting the US definition of legal blindness (visual acuity $\leq 20 / 200$ or visual field, $\leq 20^{\circ}$ equivalent to $\leq 314 \mathrm{deg}^{2}$ ) was, however, reported to be driven primarily by loss of visual acuity $(\leq 20 / 200)$ in a study of people with XLRP attributed to RPGR mutations (as opposed to patients with RHO mutations, for whom this was driven by loss of visual field). ${ }^{3}$ The median age at which individuals met the US definition of legal blindness was 45 years for those with XLRP caused by $R P G R$ mutations, compared with 77 years for people with RP due to $R H O$ mutations, the other gene most commonly associated with RP. ${ }^{3,24}$ Similarly, a US-based study of visual acuity in RP found that in the 
Table I Prevalence of RP and XLRP

\begin{tabular}{|c|c|c|c|}
\hline Location & $\mathbf{R P}$ & XLRP & Gene \\
\hline US & 1 in $3700^{\prime \prime}$ & $\begin{array}{l}-26-16 \% \text { of } \mathrm{RP} \text { cases } \\
\text { - } 22.5 \% \text { XLRP among survey } \\
\text { respondents with } \mathrm{RP}^{17}\end{array}$ & - \\
\hline France & - & - & $\begin{array}{l}\text { - RP2 I5.9\% of families with XLRP } \\
\text { - RPGR } 78.4 \% \text { of families with XLRP }\end{array}$ \\
\hline Germany & - & - & $\begin{array}{l}\text { - RP2 } 8 \% \text { of families with XLRP } \\
\text { - RPGR } 71 \% \text { of families with } X_{L R P}{ }^{14}\end{array}$ \\
\hline Spain & 1 in $8357^{18}$ & $4 \%$ of RP cases $^{18}$ & - \\
\hline UK & I in $4869^{19}$ & $\begin{array}{l}\text { - } 15.7 \% \text { RP families }^{20}(32.6 \% \\
\text { among individuals in this study) } \\
\text { - } 21.5 \% \text { RP families }\end{array}$ & - \\
\hline Japan & - & $1.8 \%$ of RP cases $^{12 a}$ & $\begin{array}{l}\text { A small-scale study attributed a similar proportion of cases of XLRP to RP2 } \\
\text { and RPGR mutations in a study of } 13 \text { males with XLRP and I } 5 \text { female carriers } \\
\text { from } 12 \text { families }{ }^{4}\end{array}$ \\
\hline
\end{tabular}

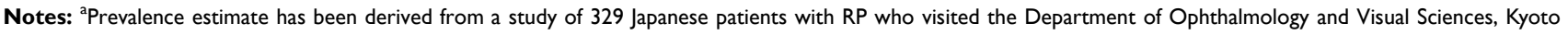
University Graduate School of Medicine, Kyoto, Japan.

Abbreviations: RP, retinitis pigmentosa; RP2, retinitis pigmentosa 2; RPGR, retinitis pigmentosa GTPase regulator; XLRP, X-linked retinitis pigmentosa.

45-54 years age group, people with XLRP were four times more likely to have visual acuity $\leq 20 / 200$ (61\%) than people with autosomal dominant RP $(15 \%){ }^{23}$

Comparing males with female carriers, a retrospective medical record review in the US reported that the disease progression rate in males with XLRP was twice that of female XLRP carriers. Most female carriers of XLRP observed over 3 years had reduced visual function in at least one eye, but only $2 \%$ became legally blind due to loss of visual acuity; this proportion may be higher in an older population. $^{8}$

\section{In the Absence of XLRP-Specific Literature, Findings for the Wider RP Population are That RP is Associated with a Significant Humanistic Burden and an Increased Mortality Risk}

In the absence of XLRP specific studies, studies summarized in Table 2 describe the humanistic burden of RP and include a qualitative assessment based on a semistructured interview of 23 people with RP in Australia, ${ }^{25}$ an online survey of 166 people with RP who have vision impairment, recruited through a patient advocacy group; ${ }^{26}$ findings from a focus group of eight people with RP who are legally blind in the US; ${ }^{27}$ a retrospective self-study of a person living with RP in Ireland; ${ }^{28}$ and a clinical assessment of 26 people with RP in Spain. ${ }^{29}$ Qualitative studies indicate that people living with RP experience difficulties with everyday tasks, psychosocial burden, and barriers to work and career. ${ }^{25,30}$

A retrospective study of patient registry and health insurance data in Korea from 2011 to 2014 identified an increased mortality risk among people with RP compared with the general population. The standardized mortality ratio (SMR) for individuals with $\mathrm{RP}$ (all ages and genders combined) was 1.56, (95\% confidence interval [CI] 1.271.90); a significantly greater risk of mortality over the general population was identified in males but not females. Suicide was the third most common cause of death among people with RP (8.9\% of deaths); suicide in males with RP aged 40-59 years was significantly more common than in the age and sex matched general population (SMR 2.61, 95\% CI 1.60-4.04), identified as the cause of the increased mortality risk. A significant association with all-cause mortality among people with RP was identified for male sex and depression, but not visual impairment, leading the authors to suggest it may be the impact of diagnosis rather than functional impairment that is the key stressor. ${ }^{31}$

With respect to differences in visual impairment, a significant inverse correlation was found between reduced visual field and vision related quality of life scores as determined using the Japanese version of the National Eye Institute Visual Functioning questionnaire-25 in 
Table 2 Themes of Humanistic Burden of RP Identified

\begin{tabular}{|c|c|c|}
\hline Theme & Key Findings & Reference \\
\hline \multirow[t]{3}{*}{ Activities of daily living } & $\begin{array}{l}\text { - Inability to drive } \\
\text { - Difficulty seeing in changing light conditions } \\
\text { - Difficulty shopping } \\
\text { - Difficulty completing household chores } \\
\text { - Difficulty reading books, menus, magazines, and newspapers } \\
\text { - Difficulty playing sports and partaking in leisure activities } \\
\text { - Difficulty orienting in unfamiliar and crowded places } \\
\text { - Difficulty using steps } \\
\text { - Accidents: falling, bumping into things, depth perception impacted by loss of peripheral vision }\end{array}$ & Senthil et al, $2017^{25 a}$ \\
\hline & $\begin{array}{l}\text { - Inability to drive } \\
\text { - Difficulty orienting and walking in unfamiliar and confined places }\end{array}$ & Bittner et al, $2010^{27 b}$ \\
\hline & - Ocular discomfort when performing daily tasks & Latham et al, $2015^{26 c}$ \\
\hline \multirow[t]{5}{*}{ Emotional } & $\begin{array}{l}\text { - Facing emotional and psychological challenges due to progressive visual loss: fear of losing } \\
\text { eyesight completely or going blind early, uncertainty about the future } \\
\text { - Feelings of frustration, shock, anxiety } \\
\text { - Embarrassment associated with being labelled disabled or blind } \\
\text { - Loss of autonomy and independence } \\
\text { - Fear of accidents, greater risk to personal safety, inability to respond in emergency situations }\end{array}$ & Senthil et al, $2017^{25 a}$ \\
\hline & $\begin{array}{l}\text { - Feelings of panic and devastation } \\
\text { - Loss of autonomy and independence }\end{array}$ & Bittner et al, $2010^{27 b}$ \\
\hline & $\begin{array}{l}\text { - Grief following diagnosis } \\
\text { - Fear of judgement: perception of use of mobility cane } \\
\text { - Fear of loss of autonomy and independence }\end{array}$ & Fourie, $2007^{28 d}$ \\
\hline & $\begin{array}{l}\text { - Dealing with negative feelings } \\
\text { - Emotion } \\
\text { - Communicating visual loss to people }\end{array}$ & Latham et al, $2015^{26 c}$ \\
\hline & - Significant negative correlation between level of depression and visual functioning & $\begin{array}{l}\text { Chacón-López et al, } \\
2013^{29 e}\end{array}$ \\
\hline \multirow[t]{2}{*}{$\begin{array}{l}\text { Social and } \\
\text { relationships }\end{array}$} & $\begin{array}{l}\text { - Missing social cues causing anxiety } \\
\text { - Dependence on others for reading, shopping, transport, and navigating in darkness } \\
\text { - Fear of being left alone and of rejection by partner }\end{array}$ & Senthil et al, $2017^{25 a}$ \\
\hline & - Spouse unable to fully understand living with vision impairment & Bittner et al, $2010^{27 b}$ \\
\hline Work/school & $\begin{array}{l}\text { - Uncertainty arising from how future visual loss affects career } \\
\text { - Loss of peripheral vision associated with difficulty reading computer screens }\end{array}$ & Senthil et al, $2017^{25 a}$ \\
\hline
\end{tabular}

Notes: ${ }^{\mathrm{a}}$ This publication describes a qualitative semi-structured interview and thematic analysis of 23 people with RP in Australia; ${ }^{\mathrm{b}}$ This publication is based on a qualitative focus groups of 8 people with RP who are legally blind in the US; 'This publication describes findings from a quantitative online survey of I66 people with RP who are vision impaired; ${ }^{\mathrm{d}}$ This publication is based on a qualitative retrospective self-study of a person with RP in Ireland; ${ }^{\mathrm{e}}$ This publication describes findings from a quantitative study in 26 people with RP conducted in Spain.

a study of 40 people with $\mathrm{RP}^{32}$ A study in 26 people with RP found a correlation between reduced visual functioning (measured using Visual Functioning questionnaire-25, version 2000) and increased level of depression (measured using Beck Depression Inventory). ${ }^{29}$ A cross-sectional study of 33 people with RP who were legally blind reported psychosocial difficulties adjusting to visual loss in three domains in particular. People with RP described experiencing difficulties in engagement with the healthcare system, reporting that they expected more understanding and support from their doctors and were not provided with adequate information about the course of their condition. In addition, people with RP reported experiencing adjustment difficulties in the domains of social environment 
(constriction or restraint of normal social activities as a result of illness) and extended family relationships (disruption or derangement in relationships with the extended family associated with the disease). ${ }^{33}$

Focus groups with eight people with RP explored the coping strategies used to manage stress related to gradual vision loss. The focus group reported that people with RP fought to maintain their independence in the face of worsening vision and demonstrated resilience by keeping vision loss in perspective and often using humor as a coping mechanism. ${ }^{27}$ Adaptative behaviors (giving oneself more time when traveling to new places, communicating one's abilities and where support is needed) and maladaptive coping strategies (smoking, eating more fast food or engaging in less physical activity) were identified as a theme in a systematic review of coping with retinitis pigmentosa. ${ }^{30}$ Use of assistive devices such as computers and technology has been reported by people with RP, and supplemented with low-vision rehabilitation training can help people with RP to adapt to gradual loss of vision. ${ }^{25,27}$ An online survey of 166 people with RP-related vision impairment found that approximately half of those surveyed used mobility aids and that those who did not tended to be younger. $^{26}$ This may reflect differences in functional vision impairment across the age groups of the RP patients surveyed. However, lack of use of mobility aids in younger people with more advanced RP may relate to the fear of judgement that has been reported. ${ }^{26,28}$

\section{The Identified Economic Burden of RP in Terms of Productivity, Healthcare and Social Care Can Reasonably Be Extrapolated to the XLRP Population}

In the absence of XLRP-specific studies describing economic burden, reports of the economic burden for the wider RP population were reviewed. The total economic burden of RP has been calculated as $£ 262.3$ million in the UK and between US\$3708.4 and US\$8790.6 million in the US in 2019, with RP comprising the largest and second largest contributor to the total cost of inherited retinal dystrophies in the UK and US, respectively. The greatest cost component was wellbeing losses (calculated through monetary value attributed to loss of disability adjusted life-years) representing $37.5 \%$ and $62.9 \%$ of the total costs for the UK and US, respectively; after this the greatest component of the economic burden was productivity. Productivity costs represented $21.8 \%$ and $13.8 \%$ of overall costs for the UK and US, respectively. Informal carer costs, healthcare system costs, and other cost categories were also identified. $^{17,34}$

A retrospective claims analysis in the US identified significantly greater overall annual healthcare costs of US\$7317 (2012 values) in people with RP compared with those without RP, predominantly due to increased outpatient costs (people with RP had an average of 2.74 more outpatient visits annually). People with RP had 2.18 additional prescriptions filled annually. This study found no meaningful increase in hospital admissions, inpatient hospital days, or emergency visits for people with RP compared with their non-RP counterparts. ${ }^{35}$ The limited impact of RP on healthcare costs is expected, as there has been no approved treatments for patients with RP. Currently the only licensed option to improve visual function has been an epiretinal prosthesis system (such as the Argus II; Second Sight Medical Products) which may be used in patients with RP who have little to no vision remaining: use of this device was reported to have a positive or mildly positive impact on the quality of life of the majority of patients in a clinical trial. ${ }^{36,41}$

With respect to other direct costs for people with RP, a US survey of people living with inherited retinal dystrophies (50\% of which had RP) found that $66.8 \%$ of those surveyed reported receiving informal care $(10.8$ hours on average per week), and $3.1 \%$ of those surveyed reported receiving formal care (average 18 hours per week). ${ }^{17}$ Patient-borne costs, as reported by a small focus group of people with RP, include travel to appointments, specialist equipment, home adaptations, and domestic help. ${ }^{37}$

In terms of productivity costs, qualitative studies describe difficulties with employment, reduced work opportunities, and a consequent financial impact for people with RP. ${ }^{25,30,37}$ People with RP reported challenges navigating in unfamiliar, confined, or busy environments resulting in vocational restrictions and sometimes a requirement to change jobs as visual acuity decreased. $^{25}$ A negative correlation between education level and vocational environment in a cross-sectional study of 33 legally blind people with RP suggests that vision challenges at school may contribute adversely to educational performance and subsequent employment. ${ }^{34}$ 
The earlier onset of XLRP may increase the impact on education compared with other forms of RP.

\section{The More Rapid Progression to Advanced Disease in XLRP May Increase the Patient Burden Compared with RP in General}

The more rapid disease trajectory associated with XLRP both onset of symptoms from childhood, and progression to blindness earlier in life - may reasonably be expected to increase the disease burden for individuals with XLRP compared with those in the wider RP population.

Although literature comparing the burden of XLRP with that of RP is limited, findings support the hypothesis that XLRP is associated with a greater burden of illness than wider RP. One study observed that, compared with the wider RP population, people with XLRP had lower perceived vision-related ability (as assessed with a modified version of the Vision Function Scale). ${ }^{38}$ The correlation between reducing visual function and increasing levels of depression in RP supports the hypothesis that humanistic burden can reasonably be expected to be greater for XLRP than for other forms of RP. ${ }^{29}$ An increase in patient burden with increasing severity of the condition has been observed in RP more generally: a study that stratified patients with RP by visual field and visual acuity found that HRQL and emotional state worsened as patients approached legal blindness (residual visual field diameter below $20^{\circ}$ and a visual

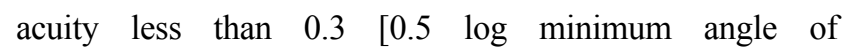
resolution]). ${ }^{39}$ Similarly, patient reports highlight the greater impact on activities of daily living associated with the progression of RP as XLRP progress, as illustrated in Figure 1. ${ }^{3,40}$ In addition, the progressive nature of RP has been reported to be a source of distress, ${ }^{25}$ hence the rapid disease trajectory observed in XLRP can reasonably be expected to have a greater impact on patients' mental health.

\section{Conclusion}

The findings of this review highlight the significant humanistic and economic burden of XLRP. As a subtype of a rare condition with no available treatments, few studies

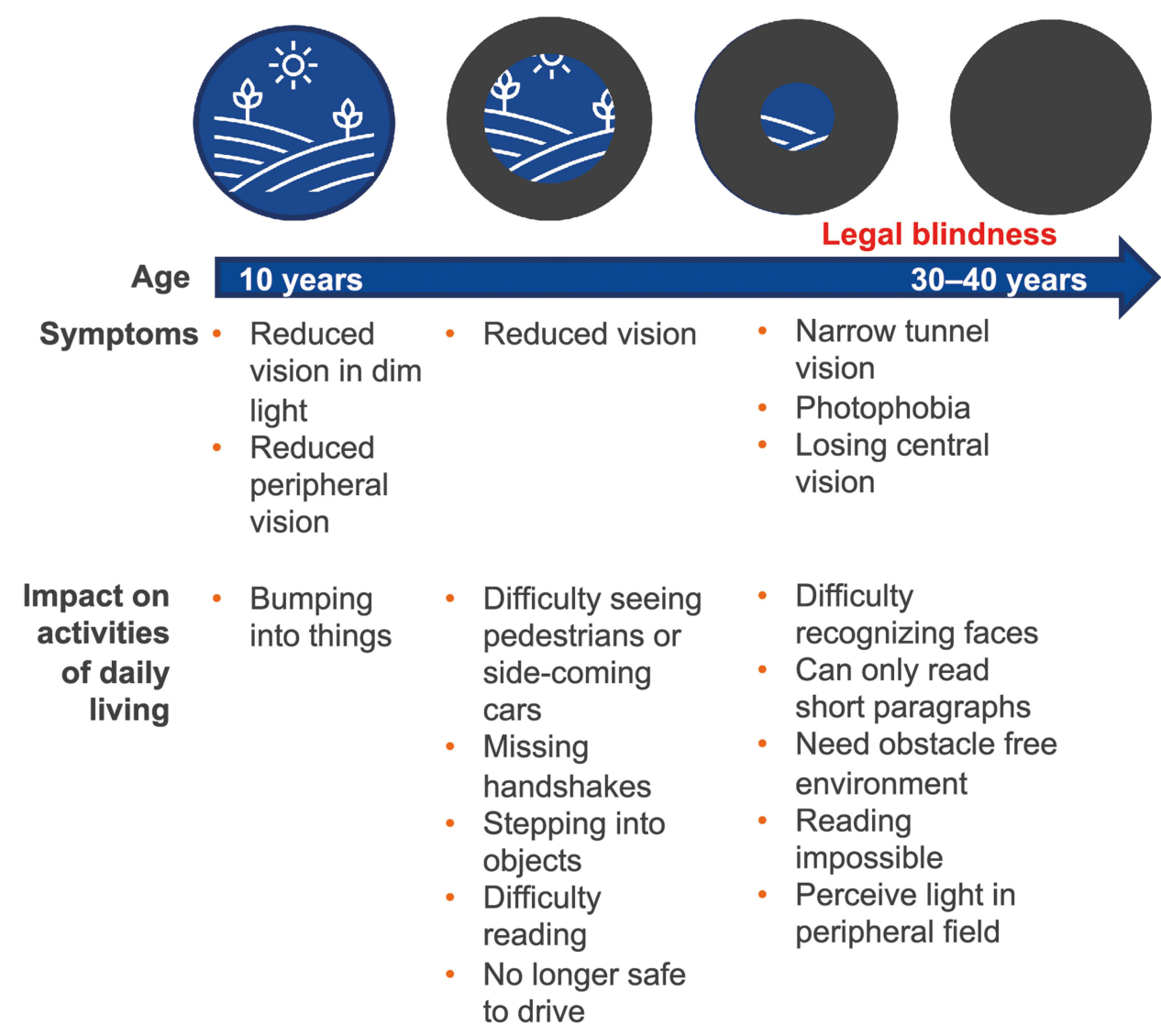

Figure I Progressive symptoms of XLRP compromise activities of daily living.

Note: Data from these studies. ${ }^{3,25,40}$

Abbreviations: RPGR, retinitis pigmentosa GTPase regulator; XLRP, X-linked retinitis pigmentosa. 
specific to XLRP have been published. This review of current literature on RP and XLRP advances the understanding of the burden of this rare disease.

People with RP reported having difficulty undertaking the activities of daily living and maintaining independence; they also experience barriers to work and career, as well as psychosocial burden. Furthermore, the impact of $\mathrm{RP}$ on patients increases with progression of the condition. Advanced RP is associated with reduced vision-related quality of life and higher levels of depression. Studies of the economic impact of RP provide a baseline assessment for XLRP. It can reasonably be assumed that XLRP is associated with a greater burden than other forms of RP, with a greater impact on education and productivity due to the younger age of those affected. In the absence of available treatments, direct healthcare costs are low for people with XLRP. However, the impact on wellbeing, productivity, caregivers, and prevalence of other conditions such as depression should be considered when assessing the economic burden. Overall, as the most severe form of RP, the burden of XLRP for patients and society may be greater than that reported for RP.

A clear limitation of this review was the lack of XLRPspecific literature. As a rare condition with no available treatment, patient advocacy groups play an active role in conducting studies and communicating the patient perspective on this condition. The goal of the gray literature review conducted in this study was to capture the patient experience.

With gene therapy for XLRP on the horizon, future research to quantify the impact of XLRP on HRQL, comorbid mental disorders, education, productivity, and other aspects are warranted. This evidence needs to be generated to raise awareness of the disease burden among key stakeholders, including policymakers, payers, and healthcare providers, who may have limited knowledge of this rare condition. Quantification of the burden of XLRP will help to evaluate benefits of the treatments currently in development.

\section{Acknowledgments}

This study was sponsored by Janssen. PRMA Consulting received funding from Janssen for the conduct of the study and development of the manuscript. All authors were involved in the project at all stages from development, execution of the review, data review and authoring of the manuscript. The abstract, methodology and preliminary results of this article were presented as a poster at Virtual ISPOR 2021.

\section{Disclosure}

Nan Li, Feng Pan, Rafal Slowik, and Jittrakul Leartsakulpanitch are employees of Janssen Research \& Development, LLC and hold stock in the company. Marie Chivers and Heather Wieffer are employees of PRMA Consulting. The authors report no other conflicts of interest in this work.

\section{References}

1. Ferrari S, Di Iorio E, Barbaro V, Ponzin D, Sorrentino FS, Parmeggiani F. Retinitis pigmentosa: genes and disease mechanisms. Curr Genomics. 2011;12(4):238-249. doi:10.2174/1389 20211795860107

2. Parmeggiani F, Sato G, De Nadai K, Romano MR, Binotto A, Costagliola $\mathrm{C}$. Clinical and rehabilitative management of retinitis pigmentosa: up-to-date. Curr Genomics. 2011;12(4):250-259. doi:10. 2174/138920211795860125

3. Sandberg MA, Rosner B, Weigel-DiFranco C, Dryja TP, Berson EL. Disease course of patients with X-linked retinitis pigmentosa due to RPGR gene mutations. Invest Ophthalmol Vis Sci. 2007;48 (3):1298-1304. doi:10.1167/iovs.06-0971

4. Kurata K, Hosono K, Hayashi T, et al. X-linked retinitis pigmentosa in Japan: clinical and genetic findings in male patients and female carriers. Int J Mol Sci. 2019;20(6). doi:10.3390/ijms20061518

5. Fahim AT, Daiger SP. The role of X-chromosome inactivation in retinal development and disease. Adv Exp Med Biol. 2016; 854:325-331.

6. Martinez-fernandez De La Camara C, Nanda A, Salvetti AP, Fischer MD, MacLaren RE. Gene therapy for the treatment of X-linked retinitis pigmentosa. Expert Opin Orphan Drugs. 2018;6 (3):167-177. doi:10.1080/21678707.2018.1444476

7. Talib M, van Schooneveld MJ, Van Cauwenbergh C, et al. The spectrum of structural and functional abnormalities in female carriers of pathogenic variants in the RPGR gene. Invest Ophthalmol Vis Sci. 2018;59(10):4123-4133. doi:10.1167/iovs.17-23453

8. Comander J, Weigel-DiFranco C, Sandberg MA, Berson EL. Visual function in carriers of X-linked retinitis pigmentosa. Ophthalmology. 2015;122(9):1899-1906. doi:10.1016/j.ophtha.2015.05.039

9. Fahim A. Retinitis pigmentosa: recent advances and future directions in diagnosis and management. Curr Opin Pediatr. 2018;30 (6):725-733. doi:10.1097/MOP.0000000000000690

10. Weiss J, Levy S. Stem cell ophthalmology treatment study: bone marrow derived stem cells in the treatment of retinitis pigmentosa. Stem Cell Investig. 2018;5(18):1-9. doi:10.21037/sci.2018.04.02

11. Boughman JA, Conneally PM, Nance WE. Population genetic studies of retinitis pigmentosa. Am J Hum Genet. 1980;32(2):223-235.

12. Oishi M, Oishi A, Gotoh N, et al. Comprehensive molecular diagnosis of a large cohort of Japanese retinitis pigmentosa and usher syndrome patients by next-generation sequencing. Invest Ophthalmol Vis Sci. 2014;55(11):7369-7375. doi:10.1167/iovs.14-15458

13. Fishman GA. Retinitis pigmentosa. Genetic percentages. Arch Ophthalmol. 1978;96(5):822-826. doi:10.1001/archopht.1978.03910 050428005

14. Bader I, Brandai O, Achatz $\mathrm{H}$, et al. X-linked retinitis pigmentosa: RPGR mutations in most families with definite $\mathrm{X}$ linkage and clustering of mutations in a short sequence stretch of exon ORF15. Invest Ophthalmol Vis Sci. 2003;44(4):1458-1463. doi:10.1167/iovs.02-0605 
15. Pelletier V, Jambou M, Delphin N, et al. Comprehensive survey of mutations in RP2 and RPGR in patients affected with distinct retinal dystrophies: genotype-phenotype correlations and impact on genetic counseling. Hum Mutat. 2007;28(1):81-91. doi:10.1002/humu.20417

16. Webb TR, Parfitt DA, Gardner JC, et al. Deep intronic mutation in OFD1, identified by targeted genomic next-generation sequencing, causes a severe form of X-linked retinitis pigmentosa (RP23). Hum Mol Genet. 2012;21(16):3647-3654. doi:10.1093/hmg/dds194

17. Deloitte Access Economics. The Socioeconomic Impact of Inherited Retinal Dystrophies (IRDs) in the United States of America (US). Retina International; 2020.

18. Najera C, Millan JM, Beneyto M, Prieto F. Epidemiology of retinitis pigmentosa in the Valencian community (Spain). Genet Epidemiol. 1995;12(1):37-46. doi:10.1002/gepi.1370120105

19. Bundey S, Crews SJ. A study of retinitis pigmentosa in the city of Birmingham. I prevalence. J Med Genet. 1984;21(6):417-420. doi:10.1136/jmg.21.6.417

20. Jay M. On the heredity of retinitis pigmentosa. $\mathrm{Br} J$ Ophthalmol. 1982;66(7):405-416. doi:10.1136/bjo.66.7.405

21. Bird AC. X-linked retinitis pigmentosa. Br J Ophthalmol. 1975;59 (4):177-199. doi:10.1136/bjo.59.4.177

22. Flaxel CJ, Jay M, Thiselton DL, et al. Difference between RP2 and $\mathrm{RP} 3$ phenotypes in $\mathrm{X}$ linked retinitis pigmentosa. Br J Ophthalmol. 1999;83(10):1144-1148. doi:10.1136/bjo.83.10.1144

23. Grover S, Fishman GA, Anderson RJ, et al. Visual acuity impairment in patients with retinitis pigmentosa at age 45 years or older. Ophthalmology. 1999;106(9):1780-1785. doi:10.1016/S0161-6420 (99)90342-1

24. Foote KG, Wong JJ, Boehm AE, et al. Comparing cone structure and function in RHO- and RPGR-associated retinitis pigmentosa. Invest Ophthalmol Vis Sci. 2020;61(4):42. doi:10.1167/iovs.61.4.42

25. Senthil MP, Khadka J, Pesudovs K. Seeing through their eyes: lived experiences of people with retinitis pigmentosa. Eye. 2017;31: 741-748. doi:10.1038/eye.2016.315

26. Latham K, Baranian M, Timmis M, Pardhan S. Emotional health of people with visual impairment caused by retinitis pigmentosa. PLoS One. 2015;10(12). doi:10.1371/journal.pone.0145866

27. Bittner AK, Edwards L, George M. Coping strategies to manage stress related to vision loss and fluctuations in retinitis pigmentosa. Optometry. 2010;81(9):461-468. doi:10.1016/j.optm.2010.03.006

28. Fourie RJ. A qualitative self-study of retinitis pigmentosa. Sage J. 2007;25(3).

29. Chacón-López H, Pelayo FJ, López-Justicia MD, et al. Visual training and emotional state of people with retinitis pigmentosa. $J$ Rehabil Res Dev. 2013;50(8):1157-1168. doi:10.1682/JRRD.2012.06.0113
30. Garip G, Kamal A. Systematic review and meta-synthesis of coping with retinitis pigmentosa: implications for improving quality of life. BMC Ophthalmol. 2019;19(1):181. doi:10.1186/s12886-019-1169-z

31. Na KH, Kim HJ, Kim KH, et al. Prevalence, age at diagnosis, mortality, and cause of death in retinitis pigmentosa in Korea-a Nationwide Population-Based Study. Am J Ophthalmol. 2017;176:157-165. doi:10.1016/j.ajo.2017.01.014

32. Sugawara T, Hagiwara A, Hiramatsu A, Ogata K, Mitamura Y, Yamamoto S. Relationship between peripheral visual field loss and vision-related quality of life in patients with retinitis pigmentosa. Eye (Lond). 2010;24(4):535-539. doi:10.1038/eye.2009.176

33. Jangra D, Ganesh A, Thackray R, et al. Psychosocial adjustment to visual loss in patients with retinitis pigmentosa. Ophthalmic Genet. 2007;28(1):25-30. doi:10.1080/13816810701201930

34. Deloitte Access Economics. The Socioeconomic Impact of Inherited Retinal Dystrophies (IRDs) in the United Kingdom. Retina International; 2019.

35. Frick KD, Roebuck MC, Feldstein JI, McCarty CA, Grover LL. Health services utilization and cost of retinitis pigmentosa. Arch Ophthalmol. 2012;130(5):629-634. doi:10.1001/archophthalmol.20 11.2820

36. da Cruz L, Dorn JD, Humayun MS, et al. Five-year safety and performance results from the argus ii retinal prosthesis system clinical trial. Ophthalmology. 2016;123(10):2248-2254. doi:10.1016/j. ophtha.2016.06.049

37. Glen F, Sidhu R, Pulfer A, Rylands A. PRO139 A patient-centric approach to cost of illness research: a case example of patient engagement to identify the hidden costs associated with blindness due to inherited retinal dystrophies. Value Health. 2019;22:S867. doi:10.1016/j.jval.2019.09.2468

38. Costela FM, Pesudovs K, Sandberg MA, Weigel-DiFranco C, Woods RL. Validation of a vision-related activity scale for patients with retinitis pigmentosa. Health Qual Life Outcomes. 2020;18 (1):196. doi:10.1186/s12955-020-01427-8

39. Azoulay L, Chaumet-Riffaud P, Jaron S, et al. Threshold levels of visual field and acuity loss related to significant decreases in the quality of life and emotional states of patients with retinitis pigmentosa. Ophthalmic Res. 2015;54(2):78-84. doi:10.1159/ 000435886

40. RNIB. Understanding retinitis pigmentosa and other inherited retinal dystrophies. $R$ Coll Ophthalmol. 2017.

41. Finn A, Grewal D, Vajzovic L. Argus II retinal prosthesis system: a review of patient selection criteria, surgical considerations, and post-operative outcomes. Clin Ophthalmol. 2018;12:1089-1097. doi:10.2147/OPTH.S137525
ClinicoEconomics and Outcomes Research

\section{Publish your work in this journal}

ClinicoEconomics and Outcomes Research is an international, peerreviewed open-access journal focusing on Health Technology Assessment, Pharmacoeconomics and Outcomes Research in the areas of diagnosis, medical devices, and clinical, surgical and pharmacological intervention. The economic impact of health policy and health systems

\section{Dovepress}

organization also constitute important areas of coverage. The manuscript management system is completely online and includes a very quick and fair peer-review system, which is all easy to use. Visit http://www.dovepress.com/testimonials.php to read real quotes from published authors. 